\title{
Acute Traumatic Primary Patella Dislocation in Children and Adolescents: A Detailed Evaluation of the Impact upon the Results
}

\author{
Bariş Yilmaz ${ }^{*}$, Evrim Şirin², Güzelali Özdemir³, Esin Derin Çiçek, Özgün Karakuş5, \\ Ahder Irem Demir ${ }^{1}$, Hasan Hilmi Muratli ${ }^{2}$ \\ ${ }^{1}$ Department of Orthopedic Surgery and Traumatology, Fatih Sultan Mehmet Education and Research Hospital, \\ Istanbul, Turkey \\ ${ }^{2}$ Department of Orthopedic Surgery and Traumatology, Marmara University Hospital, Istanbul, Turkey \\ ${ }^{3}$ Department of Orthopedic Surgery and Traumatology, Ankara Numune Education and Research Hospital, \\ Ankara, Turkey \\ ${ }^{4}$ Department of Radiology, Fatih Sultan Mehmet Education and Research Hospital, Istanbul, Turkey \\ ${ }^{5}$ Department of Orthopedic Surgery and Traumatology, Nigde State Hospital, Nigde, Turkey \\ Email: ^drbyilmaz@yahoo.com
}

How to cite this paper: Yilmaz, B., Şirin, E., Özdemir, G., Çiçek, E.D., Karakuş, Ö., Demir, A.I. and Muratli, H.H. (2018) Acute Traumatic Primary Patella Dislocation in Children and Adolescents: A Detailed Evaluation of the Impact upon the Results. Open Journal of Orthopedics, 8, 102-115. https://doi.org/10.4236/ojo.2018.83013

Received: November 14, 2017

Accepted: March 11, 2018

Published: March 14, 2018

Copyright $\odot 2018$ by authors and Scientific Research Publishing Inc. This work is licensed under the Creative Commons Attribution International License (CC BY 4.0).

http://creativecommons.org/licenses/by/4.0/

\begin{abstract}
Background and Aim: Through accurate assessment of the risk factors and structural characteristics of children presenting with acute patella dislocation, this study aimed to evaluate the probability of recurrence and the effects on treatment. Materials and Methods: Demographic and radiological evaluation was made of each case. Contributory factors to patellofemoral instability were investigated. Surgical treatment was applied to 4 (15.39\%) patients and conservative treatment to $22(84.61 \%)$. Functional status before and after treatment was evaluated using the Kujala patellofemoral scoring system. Results: The patients comprised 8 (30.77\%) males and 18 (69.23\%) females with a mean age of 13.46 years. In $15(57.69 \%)$ cases, there were patellofemoral complaints before the dislocation. The Kujala score was determined as mean 54.27 pre-treatment and 84.81 post-treatment in the conservative treatment group and mean 48.00 preoperatively and 75.25 postoperatively in the surgically treated group. No recurrence of patella dislocation was observed in any patient during the follow-up of both groups. Conclusions: Although it seems to be simple surgical intervention, as patella dislocation surgery can involve several complications, the surgical program must be very well planned and only applied to cases where necessary. With case-by-case assessment, the
\end{abstract}


probability of recurrence of patella dislocation will be removed.

\section{Keywords}

Patellofemoral Joint, Acute Patella Dislocation, Kujala Scoring

\section{Introduction}

The patellofemoral joint is a complex, highly-balanced joint which provides stability with static and dynamic soft tissue components. However, the balance can be disrupted by any event which can disrupt the normal anatomy, such as trauma, dysplasia or malalignment. In normal knees, very severe trauma is necessary for patella dislocation. Generally the mechanism of injury is external rotation of the tibia with simultaneous internal rotation of the femur causing the patella to dislocate laterally. Very occasionally, a dislocated patella is reduced by putting the knee in extension and pushing medially [1] [2].

Acute patella dislocation comprises only $2 \%-3 \%$ of all knee injuries and generally occurs in young athletes [3] [4]. In some of these patients, dislocation may recur after conservative treatment. Although surgical treatment has been recommended for all acute dislocations, as a consequence of high recurrrence rates, the contrasing view has emerged in recent years that in cases of primary dislocation, unlesss there are specific reasons, conservative treatment should be applied first [4] [5].

Through accurate assessment of the risk factors and structural characteristics of children presenting with acute patella dislocation, this study aimed to evaluate the probability of recurrence and the effects on treatment.

\section{Materials and Methods}

Approval for the study was granted by the Local Ethics Committee. The study included a total of 26 cases who presented with acute patella dislocation and had regular follow-up of a mean period of 20.19 months (range, 12 - 30 months). Initially a demographic evaluation was made of all the cases which included complaints in both knees. Patients were questioned about patellofemoral joint complaints, whether or not there was a feeling of release or rupture in the knee, a feeling of entrapment, locking or release, whether or not there was pain and if there was pain, the extent. Sensitivity in the patella edges and femoral condyles was examined, the patella fear test was applied and assessment was made of whether or not there was effusion in the knee or patellar shock, quadriceps contracture, and medial and lateral retinaculum tension or sensitivity. In addition, a record was made of the number of patella dislocations in the anamnesis, how it occurred, whether or not trauma caused the dislocation, in what direction the patella dislocated, and how it settled in place. Further investigation was made of the acccepted predisposing factors for patellofemoral 
instability of excessive femoral anteversion, genu valgum, genu recurvatum, joint hyperlaxity, patella alta, vastus medialis atrophy, hypoplasia, impaired insertion, high $\mathrm{Q}$ angle, patellar dysplasia, trochlear dysplasia and familial factors.

On first presentation at the Emergency Deprtment, anterior-posterior, lateral and tangential $\mathrm{x}$-raysof both knees were performedfor all cases. To be able to make a better evaluation when oedema decreased, magnetic resonance imaging (MRI) examination was made of the knee with patella dislocation after 3 weeks. These images were examined first for patellofemoral arthrosis, osteochondral lesions and traumatic lesions. Oedema of the Hoffa pad, oedema of the prefemoral fat pad, bone marrow oedema in the femoral condyle and the patellar bone, rupture or oedema in the structures providing medial stabilisation and effusion in the joint space were also examined. Then, the sulcus angle and depth were measured, classification was made of the Dejour and LeCoultre trochlear dysplasia, the patella was graded on the Wiberg axial graph, and patella alta was evaluated acccording to patella subluxation, the length of the tuberositas tibia-trochlear groove (TT-TG) and the Caton-Deschampsindex with the Insall-Salvati index.Radiological findings evaluated by radiologist author (EDC).

As a result of all the evaluations, the decision was taken for conservative or surgical treatment. Functional status was evaluated with the Kujala Patellofemoral Scoring Questionnaire pre-treatmment and at post-treatment mean 20.19 months (range, 12 - 30 months). In the conservative treatment, with a 3-week period of immobilisation following closed patella reduction, recovery of the medial retinaculum was expected. Then a knee brace was applied and a rehabilitation program was started. The program started with isometric quadriceps strengthening exercises, then as it was necessary in most cases, isokinetic exercises and stretching exercises for tight short muscles were added to the program. In the final stage of rehabilitation, programs increasing functional activities were added, such as running and ascending and descending stairs.

Statisical analyses of the findings obtained in the study were made using IBM SPSS Statistics 22 software (IBM, SPSS, Turkey). Conformity to normal distribution of the data of the study parameters was evaluated with the Kolmogorov-Smirnov test and it was determined that the parameters did not show normal distribution. In the comparison of the pretreatment and post-treatment parameters, the Wilcoxon sign test was used. A value of $p<0.05$ was accepted as statistically significant.

\section{Results}

The cases of the study comprised 8 (30.77\%) males and 18 (69.23\%) females with a mean age of 13.46 years (range, 9 - 16 years). As a result of the demographic evaluation, complaints of pain and a feeling of stiffness-locking and release were determined before the patellar dislocation was seen in 15 (57.69\%) cases. 
However, only 7 (35\%) patients had consulted a doctor because of these complaints. Of these, medical treatmentwas recommended for 4 cases and medical treatment together with exercise and a knee brace for 3 cases. Only 1 case was informed about the placement of the patella and the possibility of dislocation with follow-up recommended.

The patella dislocation was on the left side in $12(46.15 \%)$ cases and the right side in 14 (53.85\%). The dominant side was involved in 16 (61.53\%) cases. The dislocation occurred through trauma in 15 (57.69\%) cases, whilst going up and down stairs in $4(15.39 \%)$ cases, while doing sports in $4(15.39 \%)$ cases, while playing a game in $2(7.69 \%)$ cases and while turning over in sleep in $1(3.84 \%)$ case. Complaints related to the patellofemoral joint before the dislocaton developed were stated by 7 (26.92\%) of those whose dislocation was the result of trauma, by $4(15.39 \%)$ of those going up and down stairs, by $2(7.69 \%)$ of those doing sports, by 1 (3.84\%, case No 26$)$ playing a game and by the 1 case $(3.84 \%$, case No 16) while turning over in sleep. Reduction was made immediately by the patient themself or by a relative at the scene of the incident in $16(61.53 \%)$ cases, in the Emergency Department in $8(30.76 \%)$ cases and by a doctor or auxiliary healthcare personnel in the ambulance in 2 (7.69\%) cases (Table 1) (Figure 1(a) and Figure 1(b)).

In the radiological evaluation, osteochondral lesions were determined in 7 (26.92\%) cases, 2 of which were at an advanced stage (Type III). The osteochondral lesions were in the superolateral of the femoral lateral condyle in $2(7.69 \%)$ cases, which included 1 at advanced stage, and the lesions in the other cases were on the patellar joint surface. Oedema was determined in the Hoffa fat pad in 15 (57.69\%) cases, at levels of 8 significant and 7 minimal, and oedema was determined in the prefemoral fat pad in $11(42.30 \%)$ cases. There was widespread bone marrow oedema on both the patellar and trochlear sides in 10 $(38.46 \%)$ cases and on the patellar joint surface only in $8(30.76 \%)$ cases. Full rupture of the medial patellofemoral ligament structure was determined in 12 (46.15\%) cases and partial rupture in 14 (53.85\%) cases. The rupture was seen to be femoral in $8(30.76 \%)$ cases, patellar in $9(34.61 \%)$, in the mid-section in 3 $(11.53 \%)$ and a combined tear in $6(23.07 \%)$. Effusion in the joint space was seen at a significant level in $8(30.76 \%)$ cases and at a minimal level in 18 (69.24\%).

The sulcus angle was measured as mean $147.0^{\circ}$ (range, $135.1^{\circ}-163.9^{\circ}$ ) with $14(53.84 \%)$ cases determined with values above the critical value of $144^{\circ}$ for patellofemoral instability. According to the Dejour and Le Coultre trochlear dysplasia types, trochlear dysplasia was determined in 24 (92.30\%) of the 26 cases, with 15 cases of Type A, 8 cases of Type B, 1 case of Type C and no cases of Type D. In the classification of the patella types on the axial graph described by Wiberg, 6 (23.07\%) were Type I, 19 (73.07\%) were Type II and 1 (3.84\%) was Type III. In the relationship of the patella to the trochlea, subluxation of the patella was determined in $8(30.76 \%)$ cases. As a result of the evaluation of the length of the tuberositas tibia-trochlear Groove (TT-TG), lateral deviation of more than $15 \mathrm{~mm}$ from the tibial tubercle was determined in 1 (3.84\%) case. 
Table 1. Demographic characteristics of the cases and the treatment applied (Abbreviations, F: Female, M: Male, R: Right, L: Left, F: Fall, G: Game, S: Sport, Sl: in sleep, St: Stairs, ED: Emergency Department, A: Ambulance, PT: patient themself, LL: Lateral Loosening).

\begin{tabular}{|c|c|c|c|c|c|c|c|c|c|}
\hline Case & Age & Sex & Side & $\begin{array}{c}\text { F-UP } \\
\text { (MTHS) }\end{array}$ & Cause & Reduction & $\begin{array}{l}\text { Previous } \\
\text { Complaints }\end{array}$ & $\begin{array}{l}\text { Patellemoral } \\
\text { Instability }\end{array}$ & Treatment \\
\hline 1 & 12 & $\mathrm{~F}$ & $\mathrm{R}$ & 30 & $\mathrm{~F}$ & $\mathrm{PT}$ & No & No & Conservative \\
\hline 2 & 11 & $\mathrm{~F}$ & $\mathrm{~L}$ & 12 & G & $\mathrm{PT}$ & No & Familial history & Conservative \\
\hline 3 & 15 & M & $\mathrm{R}$ & 18 & S & ED & Yes & No & Conservative \\
\hline 4 & 16 & M & $\mathrm{R}$ & 27 & $\mathrm{~F}$ & $\mathrm{PT}$ & No & No & Conservative \\
\hline 5 & 12 & $\mathrm{~F}$ & $\mathrm{~L}$ & 20 & $\mathrm{~F}$ & ED & Yes & Genu valgum & LL \\
\hline 6 & 16 & $\mathrm{~F}$ & $\mathrm{~L}$ & 13 & St & ED. & Yes & No & OCD fixation \\
\hline 7 & 16 & M & $\mathrm{R}$ & 24 & $\mathrm{~F}$ & $\mathrm{PT}$ & yes & High Q angle & Osteotomy \\
\hline 8 & 13 & $\mathrm{~F}$ & $\mathrm{~L}$ & 26 & $\mathrm{~F}$ & $\mathrm{~A}$ & No & No & Conservative \\
\hline 9 & 12 & M & $\mathrm{R}$ & 25 & $\mathrm{~F}$ & $\mathrm{PT}$ & No & No & Conservative \\
\hline 10 & 16 & $\mathrm{~F}$ & $\mathrm{R}$ & 14 & $\mathrm{~F}$ & ED & Yes & No & Conservative \\
\hline 11 & 16 & M & $\mathrm{L}$ & 22 & St & $\mathrm{PT}$ & Yes & $\begin{array}{c}\text { Familial history, joint } \\
\text { hyperlaxity }\end{array}$ & $\mathrm{LL}+$ medial ret.repair \\
\hline 12 & 16 & M & $\mathrm{R}$ & 26 & S & $\mathrm{A}$ & No & No & Conservative \\
\hline 13 & 9 & $\mathrm{~F}$ & $\mathrm{~L}$ & 25 & $\mathrm{~F}$ & $\mathrm{PT}$ & No & Genu valgum & Conservative \\
\hline 14 & 10 & $\mathrm{~F}$ & $\mathrm{R}$ & 21 & St & $\mathrm{PT}$ & Yes & No & Conservative \\
\hline 15 & 11 & $\mathrm{~F}$ & $\mathrm{~L}$ & 26 & $\mathrm{~F}$ & $\mathrm{PT}$ & No & No & Conservative \\
\hline 16 & 16 & $\mathrm{~F}$ & $\mathrm{R}$ & 20 & $\mathrm{Sl}$ & $\mathrm{ED}$ & Yes & No & Conservative \\
\hline 17 & 13 & $\mathrm{~F}$ & $\mathrm{R}$ & 18 & $\mathrm{~F}$ & $\mathrm{ED}$ & Yes & $\begin{array}{l}\text { Excessive femoral } \\
\text { anteversiyon }\end{array}$ & Conservative \\
\hline 18 & 15 & $\mathrm{~F}$ & $\mathrm{R}$ & 19 & $\mathrm{~F}$ & $\mathrm{PT}$ & No & No & Conservative \\
\hline 19 & 16 & $\mathrm{~F}$ & $\mathrm{R}$ & 17 & $\mathrm{~F}$ & $\mathrm{PT}$ & Yes & No & Conservative \\
\hline 20 & 14 & $\mathrm{~F}$ & $\mathrm{R}$ & 15 & $\mathrm{~F}$ & $\mathrm{PT}$ & No & No & Conservative \\
\hline 21 & 13 & M & $\mathrm{L}$ & 14 & S & $\mathrm{ED}$ & No & No & Conservative \\
\hline 22 & 15 & $\mathrm{~F}$ & $\mathrm{~L}$ & 16 & $\mathrm{~F}$ & PT & Yes & No & Conservative \\
\hline 23 & 13 & M & $\mathrm{L}$ & 15 & S & $\mathrm{PT}$ & Yes & No & Conservative \\
\hline 24 & 10 & $\mathrm{~F}$ & $\mathrm{~L}$ & 23 & St & PT & Yes & No & Conservative \\
\hline 25 & 12 & $\mathrm{~F}$ & $\mathrm{~L}$ & 20 & $\mathrm{~F}$ & $\mathrm{PT}$ & Yes & Genu valgum & Conservative \\
\hline 26 & 12 & $\mathrm{~F}$ & $\mathrm{R}$ & 19 & G & $\mathrm{ED}$ & Yes & No & Conservative \\
\hline
\end{tabular}

When this case (case No 7) was examined, it was seen that there were previous patellofemoral complaints and the patella dislocation occurred as a result of trauma. In the evaluation of patella alta made with 2 indexes, patella alta was determined in 15 (57.69\%) cases (Table 2).

There were indications for surgical treatment in 4 cases. Thus, fixation in place was applied to the fractured chondral lesion in 1 case of a large osteochondral lesion, medialisation osteotomy of the tibial tubercle was applied in 1 case, lateral loosening only in 1 case and lateral loosening together with repair of the medial retinaculum in 1 case. Accordingly, surgical treatment was 
Table 2. Radiological evaluations of the cases applied (Abbreviations, F: Full, P. Partial, S: Significant, M: Minimal, Mo: Moderate, K: Kissing, NA: No available, N: Normal, L: Lateral deviation).

\begin{tabular}{|c|c|c|c|c|c|c|c|c|c|c|c|c|}
\hline Case & $\begin{array}{l}\text { Osteo } \\
\text { chondral } \\
\text { lesion }\end{array}$ & $\begin{array}{c}\text { Hoffa } \\
\text { fat pad } \\
\text { oedema }\end{array}$ & $\begin{array}{l}\text { Fat pad } \\
\text { oedema }\end{array}$ & $\begin{array}{c}\text { Bone } \\
\text { marrow } \\
\text { oedema }\end{array}$ & $\begin{array}{l}\text { Medial } \\
\text { retinaculum } \\
\text { Rupture }\end{array}$ & Effusion & $\begin{array}{l}\text { Sulcus } \\
\text { Angle }\end{array}$ & $\begin{array}{l}\text { Sulcus } \\
\text { depth }\end{array}$ & $\begin{array}{c}\text { Trochlear } \\
\text { Dysplasia } \\
\text { type }\end{array}$ & $\begin{array}{l}\text { Patella } \\
\text { Type }\end{array}$ & $\begin{array}{c}\text { Tt-tg } \\
\text { distance }\end{array}$ & $\begin{array}{c}\text { Patella } \\
\text { alta }\end{array}$ \\
\hline 1 & Femur & $S$ & Yes & K & $\mathrm{F}$ & S & 147.3 & 3.8 & B & 2 & $\mathrm{~N}$ & Yes \\
\hline 2 & No & M & Yes & K & $\mathrm{F}$ & S & 145.6 & 5.0 & B & 1 & $\mathrm{~N}$ & No \\
\hline 3 & No & S & yes & K & $\mathrm{F}$ & $S$ & 156.6 & 4.2 & C & 1 & $\mathrm{~N}$ & No \\
\hline 4 & No & M & No & $\mathrm{P}$ & $\mathrm{P}$ & M & 147.6 & 6.1 & B & 2 & $\mathrm{~N}$ & Yes \\
\hline 5 & No & No & No & $\mathrm{K}$ & $\mathrm{P}$ & M & 157.8 & 4.0 & A & 1 & $\mathrm{~N}$ & Yes \\
\hline 6 & Femur & S & Yes & No & $\mathrm{F}$ & Mo & 161.7 & 5.8 & NA & 2 & $\mathrm{~N}$ & Yes \\
\hline 7 & No & No & No & No & $\mathrm{P}$ & M & 153.9 & 4.9 & B & 2 & $\mathrm{~L}$ & Yes \\
\hline 8 & No & No & No & No & $\mathrm{P}$ & M & 156.3 & 6.0 & A & 2 & $\mathrm{~N}$ & Yes \\
\hline 9 & No & S & Yes & $\mathrm{P}$ & $\mathrm{F}$ & S & 140.0 & 4.9 & NA & 1 & $\mathrm{~N}$ & No \\
\hline 10 & No & S & Yes & $\mathrm{K}$ & $\mathrm{F}$ & S & 141.8 & 4.5 & B & 2 & $\mathrm{~N}$ & Yes \\
\hline 11 & No & No & No & No & $\mathrm{F}$ & M & 142.8 & 4.7 & B & 2 & $\mathrm{~N}$ & Yes \\
\hline 12 & No & No & No & $\mathrm{P}$ & $\mathrm{P}$ & Mo & 148.0 & 5.6 & A & 2 & $\mathrm{~N}$ & No \\
\hline 13 & Femur & S & Yes & K & $\mathrm{F}$ & $S$ & 141.4 & 2.9 & B & 2 & $\mathrm{~N}$ & Yes \\
\hline 14 & Femur & No & No & K & $\mathrm{P}$ & $\mathrm{M}$ & 140.8 & 6.1 & A & 2 & $\mathrm{~N}$ & No \\
\hline 15 & Femur & $S$ & Yes & $\mathrm{P}$ & $\mathrm{F}$ & $S$ & 141.8 & 5.1 & B & 2 & $\mathrm{~N}$ & Yes \\
\hline 16 & Patella & M & No & $\mathrm{P}$ & $\mathrm{P}$ & M & 144.3 & 3.1 & A & 2 & $\mathrm{~N}$ & No \\
\hline 17 & Femur & No & No & K & $\mathrm{P}$ & Mo & 146.6 & 3.8 & A & 2 & $\mathrm{~N}$ & No \\
\hline 18 & Patella & No & No & No & $\mathrm{P}$ & M & 148.6 & 7.2 & A & 2 & $\mathrm{~N}$ & Yes \\
\hline 19 & No & No & No & $\mathrm{P}$ & $\mathrm{P}$ & Mo & 150.1 & 3.3 & A & 2 & $\mathrm{~N}$ & Yes \\
\hline 20 & No & No & No & $\mathrm{P}$ & $\mathrm{P}$ & $\mathrm{M}$ & 142.2 & 5.2 & A & 1 & $\mathrm{~N}$ & No \\
\hline 21 & No & $\mathrm{M}$ & No & K & $\mathrm{P}$ & Mo & 150.60 & 3.8 & A & 3 & $\mathrm{~N}$ & Yes \\
\hline 22 & No & $S$ & Yes & K & $\mathrm{F}$ & $S$ & 142.9 & 4.0 & A & 1 & $\mathrm{~N}$ & Yes \\
\hline 23 & No & No & No & No & $\mathrm{P}$ & M & 151.9 & 5.4 & A & 2 & $\mathrm{~N}$ & No \\
\hline 24 & No & M & Yes & No & $\mathrm{F}$ & M & 143.2 & 5.6 & A & 2 & $\mathrm{~N}$ & Yes \\
\hline 25 & No & $\mathrm{M}$ & Yes & $\mathrm{P}$ & F & $\mathrm{M}$ & 143.9 & 7.0 & A & 2 & $\mathrm{~N}$ & No \\
\hline 26 & No & M & No & No & $\mathrm{P}$ & M & 142.4 & 4.9 & A & 2 & $\mathrm{~N}$ & No \\
\hline
\end{tabular}

applied to $4(15.39 \%)$ cases and conservative treatment to $22(84.61 \%)$ cases.

It was waited for healing of medial retinaculum with immobilisation for three months after closed reduction of patella in conservative treatment. After, rehabilitation protocol was started with knee-guard. Isometric quadriceps strengthening followed by isokinetic exercises and stretching of short muscles added when necessary. Increasing functional activities (running, climbing up stairs) were added when finishing rehabilitation protocol.

The Kujala Patellofemoral Scoring Questionnaire score was determined as mean 54.27 pre-treatment and 84.81 post-treatment (recovery score, 30.54) in the conservative treatment group and mean 48.00 preoperatively and 75.25 postoperatively (recovery score, 27.25) in the surgically treated group (p: 0.001 , 


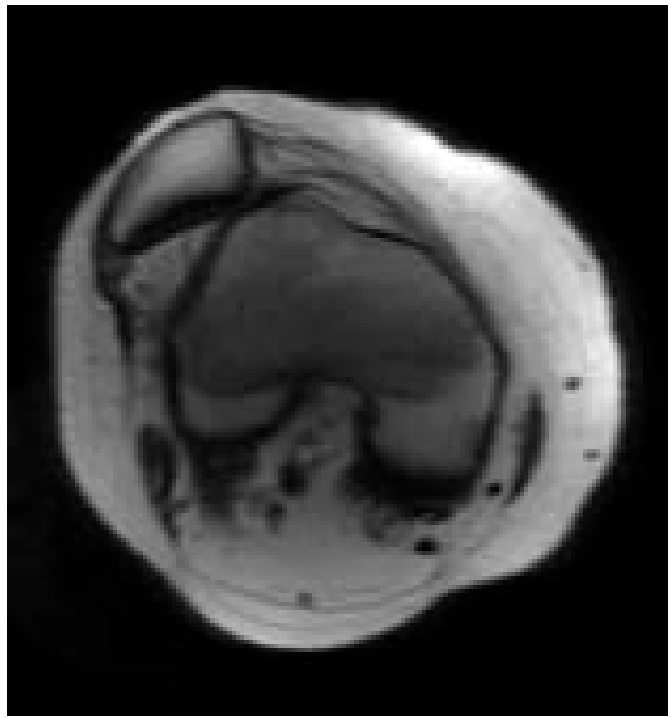

(a)

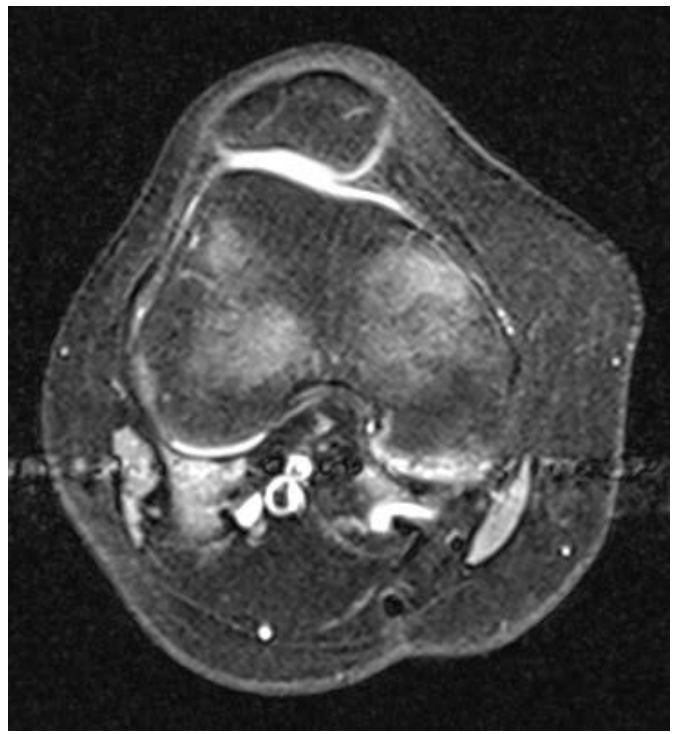

(b)

Figure 1. (a) MRI image taken in the Emergency Department of a case on presentation with acute patella dislocation. (b) MRI image taken in the Emergency Department of a case with acute patella dislocation after reduction.

$\mathrm{p}<0.01$ ) (Table 3 and Table 4) (Figure 2). No recurrence of patella dislocation was observed in any patient during the follow-up of both groups.

\section{Discussion}

Anatomically, the patella joint surface is smaller than the femoral joint surface and the whole joint surface of the patella cannot make contact with the femur at the same time. Due to this feature, the patellofemoral joint is one of the most incompatible joints in the body [6]. Apart from the anatomic properties of the 
Table 3. Evaluation of parameters pre and post-treatment (Abbreviations, P-T: Pre-treatment, Po-T: Post-treatment).

\begin{tabular}{|c|c|c|c|}
\hline & & mean $\pm \mathrm{SD}($ median $)$ & $\mathrm{p}$ \\
\hline \multirow{2}{*}{ Limping } & P-T & $2.33 \pm 1.27(3)$ & \multirow{2}{*}{$0.001^{* *}$} \\
\hline & Po-T & $4.63 \pm 0.79(5)$ & \\
\hline \multirow{2}{*}{ Weight-bearing } & P-T & $3.07 \pm 0.38$ & \multirow{2}{*}{$0.001^{* *}$} \\
\hline & Po-T & $4.93 \pm 0.38(5)$ & \\
\hline \multirow{2}{*}{ Walking } & P-T & $2.56 \pm 0.7(3)$ & \multirow{2}{*}{$0.001^{* *}$} \\
\hline & Po-T & $4.67 \pm 0.83(5)$ & \\
\hline \multirow{2}{*}{ Stairs } & $\mathrm{P}-\mathrm{T}$ & $5.56 \pm 1.19(5)$ & \multirow{2}{*}{$0.001^{* *}$} \\
\hline & Po-T & $8.11 \pm 0.89(8)$ & \\
\hline \multirow{2}{*}{ Squatting } & P-T & $3.26 \pm 0.71(3)$ & \multirow{2}{*}{$0.001^{* *}$} \\
\hline & Po-T & $4.78 \pm 0.51(5)$ & \\
\hline \multirow{2}{*}{ Running } & $\mathrm{P}-\mathrm{T}$ & $4.33 \pm 1.52(3)$ & \multirow{2}{*}{$0.001^{* *}$} \\
\hline & Po-T & $8.07 \pm 0.83(8)$ & \\
\hline \multirow{2}{*}{ Jumping } & P-T & $4.22 \pm 2.53(2)$ & \multirow{2}{*}{$0.001^{* x}$} \\
\hline & Po-T & $7.22 \pm 0.8(7)$ & \\
\hline \multirow{2}{*}{ Kneeling } & P-T & $6.81 \pm 1.0(6)$ & \multirow{2}{*}{$0.001^{* x}$} \\
\hline & Po-T & $7.93 \pm 0.38(8)$ & \\
\hline \multirow{2}{*}{ Pain } & P-T & $6.67 \pm 1.8(8)$ & \multirow{2}{*}{$0.001^{* *}$} \\
\hline & Po-T & $8.19 \pm 1.3(8)$ & \\
\hline \multirow{2}{*}{ Swelling } & P-T & $5.63 \pm 1.24(6)$ & \multirow{2}{*}{$0.001^{* x}$} \\
\hline & Po-T & $8.37 \pm 0.97(8)$ & \\
\hline \multirow{2}{*}{$P$ movement } & P-T & $3.67 \pm 1.07(4)$ & \multirow{2}{*}{$0.001^{* x}$} \\
\hline & Po-T & $6.44 \pm 1.6(6)$ & \\
\hline \multirow{2}{*}{ Thigh atrophy } & P-T & $2.67 \pm 0.96(3)$ & \multirow{2}{*}{$0.001^{* x}$} \\
\hline & Po-T & $4.93 \pm 0.38(5)$ & \\
\hline \multirow{2}{*}{ Flexion restriction } & P-T & $3.0 \pm 0(3)$ & \multirow{2}{*}{$0.001^{* *}$} \\
\hline & Po-T & $4.93 \pm 0.38$ & \\
\hline \multirow{2}{*}{ Total } & P-T & $53.07 \pm 8.45(55)$ & \multirow{2}{*}{$0.001^{* *}$} \\
\hline & Po-T & $83.22 \pm 7.72(83)$ & \\
\hline
\end{tabular}

Wilcoxon signed rank test. ${ }^{* *} \mathrm{p}<0.01$.

Table 4. Kujala evaluation.

\begin{tabular}{ccc}
\hline Patient Group & mean \pm SD & p \\
\hline Pre-treatment Kujala & $53.95 \pm 9.0$ & \multirow{0.001^{**}}{\text{Post-treatmentKujala}}{} \\
\hline
\end{tabular}

Paired samples test. ${ }^{* *} \mathrm{p}<0.01$.

patella and femur, stability of this joint between the patella and the trochlear groove is also provided by the extensor mechanism of the knee. At the same time during movements of the knee joint, several forces in different directions 


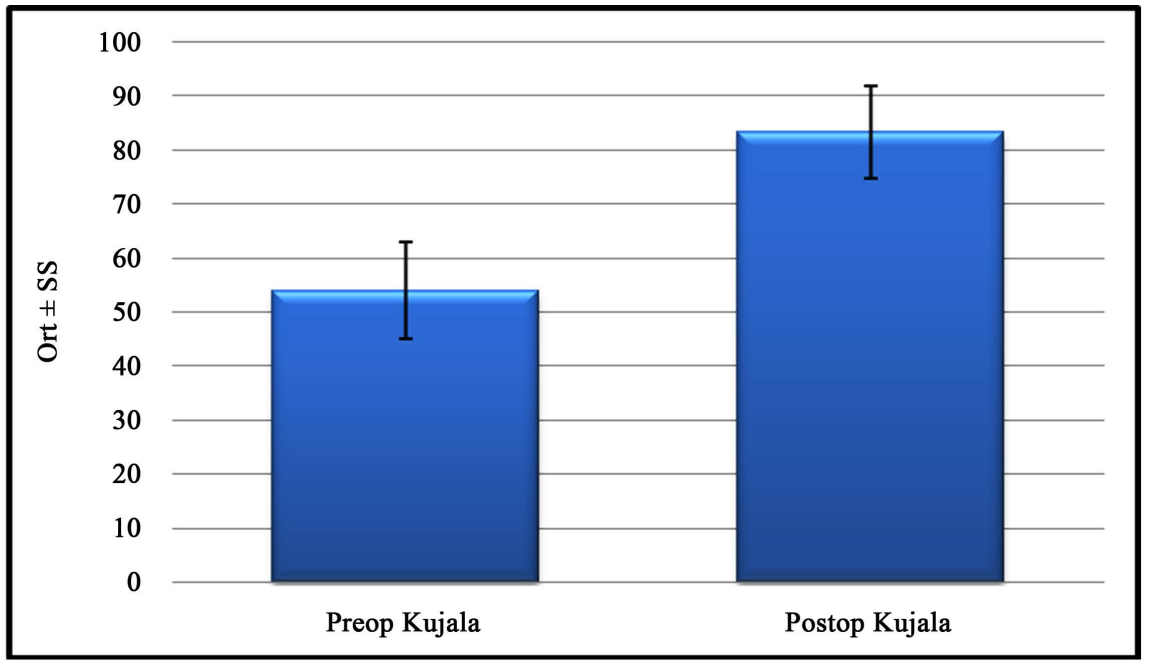

Figure 2. Graphic representation of the Kujala evaluation of the cases pretreatment and post-treatment.

affecting the patella and malalignment around the kneeare defined by the biomechanical and kinematic features of the patellofemoral joint. Therefore, it is extremely clear that more than one cause could play a role in the occurrence of patella dislocation [7]. To be able to make a decision whether to apply conservative or surgical treatment to children and adolescents presenting with acute patella dislocation, it is necessary to consider all these features in the results of the clinical and radiological evaluation.

In the current study, it was seen from the anamnesis that in approximately two thirds of the cases ( 15 of 26 cases), there were complaints related to the patellofemoral joint before the development of the acute patella dislocation. Approximately half of these, as a quarter of all the cases ( 7 of 26 cases) had consulted a doctor because of these complaints. In 4 of these 7 cases, conservative treatment was started, although only 1 patient was informed of the possibility of patella dislocation. According to these results, it can be seen that although most cases of acute patella dislocation have experienced previous problems related to the patellofemoral joint, very few are provided with information on the subject.

In cases presenting with acute patella dislocation, the stage following a good anamnesis is related to what path will be followed for treatment. A basic view of treatment for acute primary patella dislocation, is that if there is no large osteochondral fracture, if there is no intra-articular free fragment, if the patella is seen to be in place after reduction on MRI or tangential radiograph and if there are no anatomic risk factors for recurrence, the treatment should be conservative [5] [8] [9]. However, the contrasting view is that the problem should be corrected with surgical treatment before the formation of cartilage damage which can form after recurrent dislocations [10] [11]. That there is a high risk of recurrence after the first dislocation supports this view. Furthermore, it has also been reported that even if there is no dislocation, the patellofemoral joint 
complaints continue in approxiamtely half of cases. Thus, the importance is seen of radiological evaluation in taking the decision of whether to apply conservative or surgical treatment [12] [13] [14]. At this stage, great importance was given to the radiological evaluation of the cases in the current study and due to the data obtained from these tests, no case of dislocation recurrence developed.

During radiological evaluation, firstly the required evaluation of the anatomic structures of the patella and trochlea is made and this reveals the standard relationship between these two structures. Generally, patellofemoral instability occurs in the first $30^{\circ}$ of flexion and as the knee increases flexion, the patella seated in the trochlear sulcus remains stable based on the depth of the sulcus. However, the depth of this sulcus may be not be the same in every individual. MRI has been shown to be more sensitive than conventional radiography in the evaluation of the trochlear sulcus form and features [15]. If the sulcus angle is measured as $>144^{\circ}$ on MRI, it indicates trochlear hypoplasia [16]. In a recent study, it was shown that in cases where trochlear hypoplasia was suspected, the measurements of the sulcus angle together with the depth $3 \mathrm{~cm}$ proximal to the level of the tibiofemoral joint have high sensitivity and specificity in the diagnosis of trochlear dysplasia [17].

If the depth of the sulcus is $<5 \mathrm{~mm}$ this is accepted as an indicator of hypoplasia and a measurement of $<3 \mathrm{~mm}$ as dysplasia [12]. In another evaluationof the trochlea in cases with acute patella dislocation, trochlear dysplasia was determined in $96 \%$ of cases with actual patella dislocation [18]. In 5 of these 6 patients, the pathology was located in the centre or the medial trochlea [19]. According to the defined trochlear dysplasia types, the sulcus angle of all the cases was shallow and thus it can be concluded that the critical value of $144^{\circ}$ must be exceeded. In the current study, while the sulcus angle of half the cases (13 of 26 cases) was determined as shallow, trochlear dysplasia was determined in $24(92.3 \%)$ cases. In addition, in the cases determined with trochlear dysplasia, although the sulcus angle was below the critical value of $144^{\circ}$ in 11 cases, it was very close to that value $\left(140^{\circ}-143^{\circ}\right)$. It was concluded that in these cases, to be able to make a more rigorous evaluation and to direct treatment more correctly, it would not be correct to act upon only the sulcus angle and depth or only the trochlear dysplasia type but more accurate results would be provided by the use of these two assessments together.

The effect of the anatomic structure of the patella on the occurrence of patella dislocation has not been greatly discussed in literature. The most frequently seen patella dislocation is Type II and in advanced patellofemoral dysplasia, the patella is generally Type III [20]. In the current study, Type II patella was determined in approximately 75\% (19/26) of cases, which was consistent with literature.

It is known that patellofemoral contact varies with the length of the patella tendon, starting earlier or later than the degree of flexion [21]. In particular, the clinical importance of the presence of patella alta as a significant risk factor for patellofemoral instability, is greater than was previously thought [13] [22]. 
Acccording to literature, $24 \%$ of cases with patella instability have patella alta, while it has been reported to be present in 3\% of those with a stable patella [23]. Significantly higher rates of patella alta have been determined in cases where patella dislocation occurs with a very minor trauma compared to traumatic cases [24]. In the current study, in the evaluation made with the Insall-Salvati Index and the Caton-Deschamp Index, patella alta was determined in the majority $(15 / 26)$ of cases with acute patella dislocation.

One of the predisposing factors playing a role in patella dislocation is the determination of the TT-TG distance greater than $15 \mathrm{~mm}$ from the tibial tubercle, which shows lateralisation/transposition [21] [25]. By increasing the lateral pulling force of the quadriceps femoris muscle on the patella, this lateralisation of the tibial tubercle is a significant cause leading to patellofemoral disorders [26] [27]. In this case, proximal soft tissue alignment surgery alone will not be sufficient. In the current study, although patella subluxation was determined in 8 cases following reduction, the application of medialisation osteotomy of the tibial tubercle was only necessary in 1 case (case No 7) where the TT-TG distance was $>2 \mathrm{~cm}$. The other cases were treated conservatively and followed up, and as no dislocation occured during follow-up, this was an important result confirming the correctness of the treatment decision.

The localisation and treatment of medial patellofemoral ligament (MPFL) damage for acute patella dislocation is a current subject of debate in literature. In cases with TT-TG distance $<2 \mathrm{~cm}$, MPFL repair or reconstruction is recommended in the surgical treatment for acute patella dislocation. However, primary reapir of the MPFL is generally not preferred as plastic deformation which has occurred before the ligament is ruptured could cause damage in more than one area. In recent years, the majority of studies which have shown no difference between conservative and surgical treatment have been primary repair series [28] [28]. In the current study, although full or partial rupture was determined in the MPFL structure of all the cases, repair was made to only 1 case (case No 11) as it was thought that the patellar subluxation would continue without effusion or deformation of the structure.

The disadvantages of this study are its limited number of patients. Additionally, the patients were drawn from only Turkish peadiatric population; future investigations based on all populations should be conducted to provide more complete data.

\section{Conclusion}

The view has been adopted in literature that surgical treatment should be preferred for patella dislocation where there are risk factors for potential recurrence. Despite the limited number of cases, the results of the current study are extremely satisfying in respect of the decision taken for treatment as a result of the demographic and radiological evaluations and in the evaluations of the functional status made with the Kujala Patellofemoral Scoring Questionnaire applied pre-treatment and at regular intervals post-treatment. Thus it was 
concluded that accurate assessment of the risk factors and structural characteristics of children and adolescents presenting with acute patella dislocation has a significant effect on treatment and the probability of recurrence and as patella dislocation surgery can involve several complications, the surgical program must be very well planned and only applied to cases where necessary.

\section{References}

[1] Arendt, E. (2005) Anatomy and Malalignment of the Patellofemoral Joint: Its Relation to Patellofemoral Arthrosis. Clinical Orthopaedics and Related Research, 436, 71-75. https://doi.org/10.1097/01.blo.0000171543.60966.a6

[2] Fithian, D.C., Paxton, E.W., Stone, M.L., Silva, P., Davis, D.K., Elias, D.A. and White, L.M. (2004) Epidemiology and Natural History of Acute Patellar Dislocation. The American Journal of Sports Medicine, 32, 1114-1121. https://doi.org/10.1177/0363546503260788

[3] Atkin, D.M., Fithian, D.C., Marangi, K.S., Stone, M.L., Dobson, B.E. and Mendelson, C. (2000) Characteristics of Patients with Primary Acute Lateral Dislocation and Their Recovery within the First 6 Months of Injury. The American Journal of Sports Medicine, 28, 472-479. https://doi.org/10.1177/03635465000280040601

[4] Apostolovic, M., Vukomanovic, B., Slavkovic, N., Vuckovic, V., Vukcevic, M., Djuricic, G. and Kocev, N. (2011) Acute Patellar Dislocation in Adolescents: Operative versus Nonoperative Treatment. International Orthopaedics, 35, 1483-1487. https://doi.org/10.1007/s00264-011-1265-Z

[5] Cheng, B., Wu, X., Ge, H., Sun, Y.Q. and Zhang, Q. (2014) Operative versus Conservative Treatment for Patellar Dislocation: A Meta-Analysis of 7 Randomized Controlled Trials. Diagnostic Pathology, 9, 60.

https://doi.org/10.1186/1746-1596-9-60

[6] Aglietti, P., Giron, F. and Cuomo, P. (2006) Disorders of Patellofemoral Joint. In: Scott, W.N., Ed., Surgery of the Knee, Churchill Livingstone, New York, 807-936.

[7] Yilmaz, B., Çiçek, E.D., Şirin, E., Özdemir, G., Karakuş, Ö. and Muratli, H.H. (2017) A Magnetic Resonance Imaging Study of Abnormalities of the Patella and Patellar Tendon That Predispose Children to Acute Patellofemoral Dislocation. Clin Imaging, 42, 83-87. https://doi.org/10.1016/j.clinimag.2016.11.010

[8] Stefancin, J.J. and Parker, R.D. (2007) First-Time Traumatic Patellar Dislocation: A Systematic Review. Clinical Orthopaedics and Related Research, 455, 93-101. https://doi.org/10.1097/BLO.0b013e31802eb40a

[9] Panni, A.S., Vasso, M. and Cerciello, S. (2013) Acute Patellar Dislocation. What to Do? Knee Surgery Sports Traumatology Arthroscopy, 21, 275-278. https://doi.org/10.1007/s00167-012-2347-1

[10] Camanho, G.L., Viegas Ade, C., Bitar, A.C., Demange, M.K. and Hernandez, A.J. (2009) Conservative versus Surgical Treatment for Repair of the Medial Patellofemoral Ligament in Acute Dislocations of the Patella. Arthroscopy, 25, 620-625. https://doi.org/10.1016/j.arthro.2008.12.005

[11] Christiansen, S.E., Jakobsen, B.W., Lund, B. and Lind, M. (2008) Isolated Repair of the Medial Patellofemoral Ligament in Primary Dislocation of the Patella: A Prospective Randomized Study. Arthroscopy, 24, 881-887. https://doi.org/10.1016/j.arthro.2008.03.012

[12] Chhabra, A., Subhawong, T.K. and Carrino, J.A. (2011) A Systematised MRI 
Approach to Evaluating the Patellofemoral Joint. Skeletal Radiology, 40, 375-387. https://doi.org/10.1007/s00256-010-0909-1

[13] Diederichs, G., Issever, A.S. and Scheffler, S. (2010) MR Imaging of Patellar Instability: Injury Patterns and Assessment of Risk Factors. Radiographics, 30, 961-981. https://doi.org/10.1148/rg.304095755

[14] Spritzer, C.E. (2000) "Slip Sliding Away": Patellofemoral Dislocation and Tracking. Magnetic Resonance Imaging Clinics of North America, 8, 299-320.

[15] Barnett, A.J., Prentice, M., Mandalia, V., Wakeley, C.J. and Eldridge, J.D. (2009) Patellar Height Measurement in Trochlear Dysplasia. Knee Surgery Sports Traumatology Arthroscopy, 17, 1412-1415. https://doi.org/10.1007/s00167-009-0801-5

[16] Salzmann, G.M., Weber, T.S., Spang, J.T., Imhoff, A.B. and Schöttle, P.B. (2010) Comparison of Native Axial Radiographs with Axial MR İmaging for Determination of the Trochlear Morphology in Patients with Trochlear Dysplasia. Archives of Orthopaedic and Trauma Surgery, 130, 335-340. https://doi.org/10.1007/s00402-009-0912-y

[17] Pfirrmann, C.W., Zanetti, M., Romero, J. and Hodler, J. (2000) Femoral Trochlear Dysplasia: MR Findings. Radiology, 216, 858-864. https://doi.org/10.1148/radiology.216.3.r00se38858

[18] Dejour, D. and Le Coultre, B. (2007) Osteotomies in Patello-Femoral İnstabilities. Sports Medicine and Arthroscopy Review, 15, 39-46. https://doi.org/10.1097/JSA.0b013e31803035ae

[19] Biedert, R.M. and Bachmann, M. (2009) Anterior-Posterior Trochlear Measurements of Normal and Dysplastic Trochlea by Axial Magnetic Resonance Imaging. Knee Surgery, Sports Traumatology, Arthroscopy, 17, 1225-1230. https://doi.org/10.1007/s00167-009-0824-y

[20] Dejour, D. and Saggin, P. (2010) The Sulcus Deepening Trochleoplastythe Lyon's Procedure. International Orthopaedics, 34, 311-316. https://doi.org/10.1007/s00264-009-0933-8

[21] McNally, E.G., Ostlere, S.J., Pal, C., Phillips, A., Reid, H. and Dodd, C. (2000) Assessment of Patellar Maltracking using Combined Static and Dynamic MRI. European Radiology, 10, 1051-1055. https://doi.org/10.1007/s003300000358

[22] Wittstein, J.R., Bartlett, E.C., Easterbrook, J. and Byrd, J.C. (2006) Magnetic Resonance İmaging Evaluation of Patellofemoral Malalignment. Arthroscopy, 22, 643-649. https://doi.org/10.1016/j.arthro.2006.03.005

[23] Dejour, H., Walch, G., Nove-Josserand, L. and Guier, C. (1994) Factors of Patellar Instability: An Anatomic Radiographic Study. Knee Surgery Sports Traumatology Arthroscopy, 2, 19-26. https://doi.org/10.1007/BF01552649

[24] Geenen, E., Molenaers, G. and Martens, M. (1989) Patella Alta in Patellofemoral İnstability. Acta Orthopædica Belgica, 55, 387-393.

[25] Shakespeare, D. and Fick, D. (2005) Patellar İnstability-Can the TT-TG Distance Be Measured Clinically? Knee, 12, 201-204. https://doi.org/10.1016/j.knee.2003.08.007

[26] Peers, K.H. and Lysens, R.J. (2005) Patellar Tendinopathy in Athletes: Current Diagnostic and Therapeutic Recommendations. Sports, 35, 71-87. https://doi.org/10.2165/00007256-200535010-00006

[27] Emami, M.J., Ghahramani, M.H., Abdinejad, F. and Namazi, H. (2007) Q-Angle: An İnvaluable Parameter for Evaluation of Anterior Knee Pain. Archives of Iranian 
Medicine, 10, 24-26.

[28] Zaffagnini, S., Grassi, A., Marcheggiani Muccioli, G.M., Luetzow, W.F., Vaccari, V., Benzi, A. and Marcacci, M. (2014) Medial Patellotibial Ligament (MPTL) Reconstruction for Patellar Instability. Knee Surgery, Sports Traumatology, Arthroscopy, 22, 2491-2498. https://doi.org/10.1007/s00167-013-2751-1

[29] Zhang, G.Y., Zheng, L., Ding, H.Y., Li, E.M., Sun, B.S. and Shi, H. (2015) Evaluation of Medial Patellofemoral Ligament Tears after Acute Lateral Patellar Dislocation: Comparison of High-Frequency Ultrasound and MR. European Radiology, 25, 274-281. https://doi.org/10.1007/s00330-014-3407-3 